\title{
The Architecture Of Management Accounting Systems Change: A Multidimensional Approach
}

John J. Williams, Nanyang Technological University, Singapore Alfred E. Seaman, McMaster University, Canada

\begin{abstract}
We extend the model developed by Williams and Seaman [Williams, J. J. \& Seaman, A. E. (2001). Predicting change in management accounting systems: national culture and industry effects. Accounting, Organizations and Society, 26, 443-460] and utilize the same sample of 93 Chinese family owned businesses to test the multivariate relationship between a set of operational effectiveness measures and a set of changes in management accounting and control systems components under the contingency effects of size, organizational capacity, intensity of competition and centralization. Significant relationships emerge for high intensity of competition, high centralization, and low and high levels of organizational capacity. Variables of major importance in these relationships converge to form two larger patterns of a structural and environmental nature, which are consonant with the core national cultural values of Singapore documented in the contemporary cross-cultural management control literature.
\end{abstract}

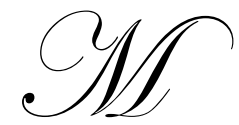

anagement accounting and control systems (MACSs) consist of dynamic components overarching planning, controlling, decision making and reward systems (Otley, 1980; Flamholtz et al., 1985; Merchant, 1989) that are thought to collectively support firms' operational effectiveness (Cooper, Sinha \& Sullivan, 1995; Porter, 1996; Granlund, 1997; Granlund \& Lukka, 1998). Casual observation and new practices reveal that these components are not static in nature but the literature is remarkably silent about the phenomena of MACSs change in general. Libby and Waterhouse (1996) explore several organizational and economic determinants of MACS changes for a sample of Canadian manufacturing firms. Williams \& Seaman (2001) replicate their study, using a sample of Singaporean firms, and demonstrate the importance of the power distance value emanating from Hofstede's $(1980,1982,1991)$ national culture framework. However, neither study examines the important linkage between MACS changes and operational effectiveness, which is addressed in this paper.

Recent literature on antecedents and consequences of management accounting controls is pressing for more empirically complex nomological frameworks (e.g., Shields \& Shields, 1998). For some time, researchers have been urged to consider a range of effectiveness measures to understand the appropriateness of particular accounting control systems (Hopwood, 1978; Otley, 1980; Merchant, 1985). In a similar vein, Harrison \& McKinnon (1999) champion a more "gestalt approach" to uncovering the relative importance of cultural and non-cultural variables in explaining control phenomena. They even call for more sequential work from individual researchers and believe that a central focus on "ingroups ... in modern Chinese organizations" (p. 503) is of interest. Building on the works of Parsons (1964), Rokeach (1973) and Schein (1985), it appears as though Lachman, Nedd \& Hinings (1994) support this type of emphasis and suggest that "efforts should be directed at identifying the core values of particular cultural settings, and examining their wider impact on organizational practices" (p. 42).

Readers with comments or questions are encouraged to contact the authors via email. 
Some of this complexity might be captured by invoking a multidimensional design strategy whereby a set of changes in MACS components is analyzed in unison with a set of operational effectiveness measures. In this paper we test this relationship utilizing the same MACS components that Williams \& Seaman (2001) examine and assess whether their independent variables moderate this relationship. The identical sample of 93 Chinese familyowned businesses constitutes the database. While a multivariate approach may mitigate some of the underspecification issue, knowledge of the larger pattern of important MACSs components could be traced through shifting environmental disturbances, such as national industrial policies or globalization effects. Other benefits could include more synergistic clarity in mapping MACS changes on to possible behavioral responses in the firm, or directing the import of cross-national control systems to areas of organizational strength rather than confronting conflict and tension where differences exist.

First, we draw inferences from past literature to suggest that: (1) control systems, including MACSs, contain multiple elements that should be assessed collectively; (2) performance outcomes are not adequately captured by a singular measure, even if aggregated; and (3) elements in both sets are inextricably linked, implying simultaneous and not sequential analysis. Theoretically, these characteristics appear to advocate a research problem that "almost demand(s) canonical analysis" (Kerlinger, 1973, p. 652).

Secondly, we assess the moderating effects of the same independent variables used by Libby \& Waterhouse (1996) and Williams \& Seaman (2001) (i.e., concentration of authority, size, learning capacity and competition) to uncover any potential convergence in the dominant patterns that may emerge in the canonical analyses. Past contingency literature (Hopwood, 1972; Bruns \& Waterhouse, 1975; Merchant, 1981; Otley \& Wilkinson, 1988; Hofstede, 1991; Chow, Shields \& Wu, 1999) raises the expectation that contextual and/or structural variables could influence the canonical relationship and the emergent patterns as a whole. Unfortunately, specificity concerning the issue of MACSs change and operational effectiveness at the macro level is largely absent.

Thirdly, we hold cultural ethnicity and the corresponding national value structure constant through the sample choice for methodological reasons and to facilitate interpretation of the results. The literature criticizes the omission of value dimensions or the failure to recognize the differential intensity of cultural norms, yielding empirical results that are difficult to interpret and compare (Harrison \& McKinnon, 1999). Other cultural literature questions the unbundling of interrelated and omnipresent values in an individual's host social setting (Chow et al., 1999). Rather, it is the relative importance of values in a given culture that is expected to influence the organizational setting and related control processes (Lachman et al., 1994).

\subsection{Developing testable relationships}

\subsection{Linkage between MACSs and operational effectiveness}

Formal management accounting systems are pervasive within an organization, designed to supply information that is congruent with the organization's goals (Hopwood, 1972; Horngren, 1972). Changes made to these systems, however, function in reciprocity with intended objectives or purposes (Otley, 1978; Merchant, 1981, 1985), akin to a scissors blades. Design specifications in the accounting literature typically treat MACS components, such as budgeting or controllability systems, as independent variables that affect performance outcomes. However, Otley (1978) concludes that the latter are, de facto, independent variables and Merchant (1985, p. 71) observes that this is an appropriate stance for all control-related studies. These views augment the proposition that realized MACS changes, which are no longer a priori design considerations, occur in concert with the preferred operational performance goals chosen by the decision-making authority. Our concern is not to engage in the cause-effect debate but, rather, to analyze the significant conjuncture of the two for significant patterns of important variables.

Other literature pertaining to cross-national cultural research underscores the complexity of this basic interrelatedness. Chow, Shields \& Chan (1991) maintain that control system components operate simultaneously, and the functioning of a management control system "include(s) tradeoffs across both control components and objectives (Chow, Kato \& Shields, 1994, p. 387). The latter suggest a solution: develop "multidimensional representations ... of individual's preference for sets of management control" (p. 397). Harrison \& McKinnon (1999) advocate the 
need to comprehend how MACS are "constituted holistically" in different cultural settings and how their "measured dynamics" operate (p. 500). Thus, a methodological strategy that deals simultaneously with composite sets of MACS changes and performance outcomes appears to be endorsed in the literature. It is consistent as well with the theoretical framework developed by Lachman et al. (1994) whereby patterns of core versus peripheral values affect congruent patterns of organizational structure and effectiveness in particular cultural settings.

Our approach to analyzing the interconnectedness of MACS changes and operational effectiveness assumes that multiple elements of the latter are antecedent to the more intractable consequent variable of organizational effectiveness (Steers, 1975; Campbell, 1977). However, even at the operational level there is not a general consensus, but there is sufficient literature to support a multidimensional perspective that encompasses outcomes, processes and commitment that are commensurate with the dominant organization coalition under specific situations (Steers, 1977; Cameron \& Whetten, 1981; Quinn \& Cameron, 1983).

For example, building on Perrow's $(1961,1970)$ differentiation of official versus operative goals, Daft (1986, pp. 86-7) identifies five types of operative goals applicable to the organization level. Briefly stated, environmental goals reflect reputation and secure legitimacy; output goals pertain to goal attainment in terms of defining the business and identifying consumer needs; systems goals maintain morale; product goals relate to quantity and quality in terms of physical attributes and service; and, "means-end" processes in technical operations manifest efficiency and innovation. These performance criteria would seem to envelop the formal informational purposes espoused in a variety of academic and practitioner sources that have their roots in the components of MACS changes. Moreover, multiple measures of performance are relevant instead of single measures because they are not only "likely to affect the nature of accounting systems but also, and more importantly, because they form the criterion against which the effects of different configurations of control must be evaluated" (Otley, 1980, pp. 423-4).

The extension of these collective arguments to the relation between changes in MACS components and operational effectiveness in canonical form has merit but lacks empirical foundation. This imprecision for prediction purposes warrants a research question (for the moderating effects to follow as well) but we defer to testing a hypothesis, stated in null form, for ease of exposition.

H1: $\quad$ There is no general relationship between the set of changes in MACS components and the set of operational effectiveness measures.

\subsection{Moderating effects}

A prolific literature has established that consequences of managerial control systems (organizational or individual) and the specific controls, themselves, are contingent on various organizational structures and contexts (Child, 1981; Otley \& Wilkinson, 1988: Fisher, 1995). Antecedent to this complexity are the effects of national culture, with its attendant set of core and peripheral values, which is a design constant in the present study and not measured directly. ${ }^{1}$ This approach meshes with past literature which views the totality of indigenous cultural values as being embedded in the individual and manifested appropriately in the particular social environment (Hofstede, 1980, 1991; Lincoln \& Kalleberg, 1990; Lachman et al., 1994; Harrison \& McKinnon, 1999).

\subsubsection{Concentration of authority}

Hofstede's $(1980,1991)$ taxonomy of national culture is the preferred benchmark in the literature for locating Singapore high on the power distance norm. Williams \& Seaman (2001) trace the theoretical linkage of the power distance dimension to the Aston (Pugh, Hickson, Hinings \& Turner, 1968; Pugh et al., 1969) dimension of Concentration of Authority, which is commonly interpreted in terms of centralization or decentralization. They also provide an extensive review of the cross-cultural research literature that features centralization of power as the hallmark of local Singaporean companies. Consistent with expectations, Williams \& Seaman (2001) report that centralization is the most significant predictor of changes in MACS components whereas Libby \& Waterhouse (1996) did not find decentralization to be a significant correlate in the Canadian sample. 
These arguments, while necessary, are not sufficient to assess the moderating effects of centralization on the canonical relation under study here for two reasons. First, empirical work based on Hofstede $(1980,1991)$ fails to make explicit that centralization is a relative concept, even among Chinese family-owned businesses. For example, the founding family patriarch unreservedly maintains power over all strategic business decisions, allocates rewards, directs the social networking of customers and suppliers (i.e., guanxi), and determines the acceptable inner circle of managers, notwithstanding the implementation of bureaucratic controls or procedures (Tong \& Yong, 1997; Tsui-auch, 2001). He sees the entire spectrum of core and non-core business operations, including important operational objectives and the ultimate goal of survival. It is this clairvoyance that connects hierarchical authority to critical operating systems (including changes) and operational effectiveness.

Secondly, the notion of centralized power and diffused decision-making authority is easily assimilated into the family business structure, depending on the number of offspring directing businesses that are non-core but under the family umbrella. In many instances, children of the patriarch are educated overseas, exposed to state-of-the-art management practices and accounting controls, and have a greater propensity to co-opt professional managers who take charge of operational, day-to-day matters, including more experimentation with new technologies relative to the patriarch (Ng, 1992; Whyte, 1996). Thus, the potential exists for a powerful controlling patriarch, and less centralized decision making via family members that is also less coordinated with all components of MACS (including changes) and operational effectiveness.

H2: $\quad$ There is no general relationship between the set of changes in MACS components and the set of operational effectiveness measures where: (a) centralization is high; and (b) centralization is low.

\subsubsection{Intensity of competition}

The term intensity of competition originates in the work of Khandwalla (1972) and later Miles \& Snow (1978). It is a strategic organizational variable that pertains to specific external referents including price, promotion, distribution, product quality, and variety competition. However, it tends to be confused in the literature with Duncan's (1972) construct of perceived environmental uncertainty, which includes external and internal factors. Tyman, Stout \& Staw (1998, p. 26) firmly stress that intensity of competition refers to an organization's external environment, perceptions of that environment and, most importantly, perceptions that emanate from top managers.

Past empirical research reports significant correlations between intensity of competition and management controls (Khandwalla, 1972), organization structure and information system characteristics (Gordon \& Narayanan, 1984), and business unit performance (Govindarajan, 1984), which is an organization-level variable. However, both Libby and Waterhouse (1996) and Williams and Seaman (2001) report weak support for the relation between changes of MACS components and intensity of competition. Alternatively, an external environment that poses little competition would not induce the same information demands, nor necessarily pressure the organization to invest in numerous systems changes.

H3: $\quad$ There is no general relationship between the set of changes in MACS components and the set of operational effectiveness measures when: (a) intensity of competition is high; and (b) intensity of competition is low.

\subsubsection{Organizational capacity}

Libby and Waterhouse (1996, p. 141) argue that the state of existing management accounting expertise in an organization reflects its capacity to learn new knowledge and to absorb new technologies. They refer to Cohn \& Levinthal's (1990) thesis that specific knowledge in an area increases the organization's awareness of new developments in the external environment and the ability to assimilate it internally. Therefore the expertise manifested in the existing number of MACS components creates the momentum to expand the knowledge base which, in turn, fuels more change.

Libby \& Waterhouse (1996) thus predicted, and found, a positive relationship between organizational ca- 
pacity and high rates of change in MACSs and the decision-making component. Williams \& Seaman (2001) report a weak positive relation and negative relation between organizational capacity and changes in the controlling component and costing component, respectively. In the present study, however, the focus is on the entire set of changes in MACS components, which may possibly disadvantage a smaller base of expertise, handicap the infusion of innovation and, therefore, the capacity to change. This state could occur if attention is limited to change in only one or several MACS components rather than emphasizing the entire set.

H4: $\quad$ There is no general relationship between the set of changes in MACS components and the set of operational effectiveness measures where: (a) organizational capacity is high; and (b) organizational capacity is low.

\subsubsection{Size}

Early contingency research (Hage \& Aiken, 1967; Blau, 1970; Child, 1973) shows that larger firms have different dimensions of structure relative to smaller firms, reflected in more decentralization of authority, formalization, standardization and complexity, among others. The conventional argument is that larger organizations may have more resources to possibly invest in upgrading MACSs, for example, by modifying or changing them. But the effects of size and growth become interwoven (Daft, 1986), with smaller firms possibly sacrificing resources to expand or improve administrative systems such as MACSs. Also, the influence of size alone on organizational effectiveness is not supported in the literature (Child, 1977).

Libby \& Waterhouse (1996) note that Kimberly \& Evanisko (1981) found a positive association between technical change and size but not between administrative change and size. The former authors did not find any significant relationships between changes to components of MACSs and size. Williams \& Seaman (2001), however, found size to be positively related to changes in the controlling component but negatively related to changes in the decision-making component. Hence, there is no compelling evidence to associate small- or large-sized Chinese family-owned businesses with the canonical relation examined here.

H5: $\quad$ There is no general relationship between the set of changes in MACS components and the set of operational effectiveness measures for: (a) large firms; and (b) small firms.

\subsection{Method}

\subsection{Sample}

The detailed sampling procedures and profile of the sample firms are identical to Williams \& Seaman (2001). However, three points need to be re-emphasized. First, while all 93 Chinese family-owned firms are registered as private companies in Singapore, none are listed on the Singapore Stock Exchange and, therefore, the complexity of their MACSs is not compromised by external regulations from this source. Secondly, we did not measure "ingroup" status formally but a significant number of controllers and/or chief financial officers that responded were family members or kin. Thirdly, the substantial tenure of the sample respondents (average of 9 years and current position for 4.8 years) indicates a solid comprehension of the family business and requisite knowledge to understand the breadth of the research instrument.

\subsection{Measures of variables}

Measures of the moderating variables and the five components of MACS changes are taken directly from Williams \& Seaman (2001). The five components include changes to the planning, controlling, costing, directing and decision-making systems and they are reproduced in Appendix 1. The measure of intensity of competition is based on Khandwalla (1977) while size is measured by the natural logarithm of the number of employees in the organization. The Aston Concentration of Authority scale (Pugh et al., 1969; Inkson, Pugh \& Hickson, 1970) is used to measure centralization. The measure of intensity of organizational capacity to learn is based on Libby \& Waterhouse (1996) and Williams \& Seaman (2001). 
A seven-item questionnaire developed by Van de Ven \& Ferry (1980) for use at the organizational level (Daft, 1986, 1992) measures operational effectiveness. This instrument was developed, revised and improved in four successive iterations over a seven-year period as part of Van de Ven and Ferry's Organizational Assessment Instrument. Williams et al. (1990) and Mcintosh \& Williams (1992) use it in managerial accounting studies at the departmental level. The instrument is modified slightly in this study to ask respondents "How did the major operating components of your business perform on average over the period January 1995 to end-June 1997 on the following dimensions: (a) The quantity or amount of work produced?; (b) The quality or accuracy of work produced ?; (c) The number of innovations or significant new ideas introduced?; (d) Reputation achieved for work excellence?; (e) Attainment of production or service goals?; (f) Efficiency of operations?; and (g) Morale of operating personnel?". Each question was fully anchored on a five-point Likert scale ranging from (1) far below average to (5) far above average. $^{2}$

\subsection{Statistical design}

Canonical correlation analyses is used to examine the relationship between changes in MACS components as a set of independent variables (i.e., predictor set) and the set of operational effectiveness measures as dependent variables (i.e., criterion set), where variates are computed from both sets of variables. The statistical algorithm generates linear variates, which maximally correlate with each other $(\mathrm{Rc}=1)$, and the relationship is interpreted via the canonical correlation R. In addition, standardized canonical coefficients (weights) are produced for each variable analogous to standardized beta coefficients in multiple regression analysis.

A standardized canonical coefficient represents the marginal contribution of a given variable from one set on the other set considering the interaction of all variables simultaneously. Standardized coefficients have potentially meaningful interpretation only when there is a significant relationship between the criterion and predictor sets. Cooley \& Lohnes (1971) support this approach particularly for highly correlated criterion variables.

\subsection{Results}

\subsection{Descriptive and canonical correlation statistics}

Table 1 shows the descriptive statistics for all variables. Excluding size, the match between the actual and theoretical range for each variable measure is acceptable. Notably, the scores for each effectiveness measure span the entire theoretical range. Table 2 displays the Pearson zero-order correlation coefficients between changes in MACS components and the effectiveness variables. ${ }^{3}$ With the exception of several significant but low correlations between changes in costing systems and several effectiveness variables, the bivariate findings seem to be of minimal value. To explore the low and high effects of the moderating variables, we dichotomize each one at its median. Simple $\mathrm{t}$-tests confirm significant differences: centralization $(\mathrm{t}=13.9 ; \mathrm{p}<0.00)$; competition $(\mathrm{t}=13.2 ; \mathrm{p}<0.00)$; capacity $(\mathrm{t}=12.8 ; \mathrm{p}<0.00)$; and size $(\mathrm{t}=13.7 ; \mathrm{p}<0.00)$.

Results of the canonical correlation tests are summarized in Table 3 but only for the significant roots. ${ }^{4}$ Insignificant relationships are not reported because their standardized weights cannot be interpreted in a meaningful way. One significant function ( $R c=0.512 ; \mathrm{p}<0.013)$ emerges for the total sample, which supports rejection of the null hypothesis H1. Therefore, there is evidence for a positive association between the set of changes in MACS components and the set of effectiveness variables. There is no significant function for the moderating effect of low centralization on the canonical relationship, thus not allowing the rejection of hypothesis H2b. However, one significant function $(\mathrm{Rc}=0.705 ; \mathrm{p}<0.044)$ emerges for high centralization which supports the rejection of hypothesis H2a. This evidence means that the positive association between the variate of changes in MACS components and the effectiveness variate holds when the concentration of authority is high but not when it is dispersed.

Similarly, one significant function ( $\mathrm{Rc}=0.713 ; \mathrm{p}<0.006)$ appears for the moderating effect of high competition, which does not support the acceptance of hypothesis H3a, but there is no significant function for the moderating effect of low competition and hypothesis $\mathrm{H} 3 \mathrm{~b}$ must be accepted. However, significant functions emerge for both low $(\mathrm{Rc}=0.688 ; \mathrm{p}<0.019)$ and high $(\mathrm{Rc}=0.690 ; \mathrm{p}<0.018)$ levels of organizational capacity to learn. This 
evidence is sufficient to reject both null hypotheses H4b and H4a, respectively. Surprisingly, no significant functions arise for the moderating effects of either large or small firms, which means that hypothesis H5a and H5b can not be rejected.

Overall, the canonical $\mathrm{R}$ is noticeably higher for every significant root as compared to the total sample. Also the percentage of variance explained is higher in every case except for the high capacity root and it is only marginally less. Together, these findings substantiate the more potent moderating effects, which are otherwise blurred in the total sample results.

\subsection{Additional analysis}

\subsubsection{Convergent patterns among the canonical coefficients}

The merit of analyzing the many-to-many patterns of association with canonical correlation, as opposed to one-to-many patterns resulting from regression analysis, lies in the potential for uncovering a richer explanatory model of holistic relationships that are otherwise intractable. The series of canonical coefficients for the moderating variables in Table 3 reveal extremely important variables in each set but it is difficult to discern any distinct composite picture. In Figure 1 the largest coefficients from Table 3 are arrayed according to the contingency variables moderating the canonical relationships. ${ }^{5}$ Two patterns emerge from this procedure.

Moderating variables of a structural nature cluster in a unique manner. All are associated with an emphasis on controlling systems change and a de-emphasis on either planning or directing systems change. Further, these combinations primarily converge to enhance quality, as well as efficiency and morale, but all of them de-emphasize the quantity criterion. Within this framework, interpretation is somewhat straightforward. For example, under a contingency state of high capacity, more changes to controlling systems while holding all other MACS component changes constant would increase morale and decrease quantity the most. Since planning systems change has a negative coefficient, de-emphasizing this variable even more, in conjunction with more changes to controlling systems, would increase morale and decrease quantity even further. Other specific structural effects can be interpreted similarly.

The environmental pattern depicted in Figure 1 is much less complex. A high competitive environment is positively associated with an emphasis on decision-making systems change and a de-emphasis on costing systems change that converge to increase efficiency, with no important negative consequences.

One concern with the structural gestalt, especially with a focus on only the largest coefficients, is whether the ordering of the standardized coefficients in Table 3 for centralization (column 2), and low and high levels of learning capacity (columns 4 and 5) represent a true ranking. Actually, this matter is one of inter-test reliability among the clusters of predictor and criterion coefficients. We explore this issue by using the Kendall coefficient of concordance $\mathrm{W}$ to test for the agreement of rankings in the coefficients of the three respective predictor sets of changes in MACS components and the corresponding three criterion sets of effectiveness measures. The value of $\mathrm{W}$ for the rankings of the predictor sets is $0.641(\mathrm{p}<0.02 ; \mathrm{n}=5$; one-tailed test) while the value of $\mathrm{W}$ for the three criterion sets is 0.481 ( $\mathrm{p}<0.05 ; \mathrm{n}=7$; one-tailed test). These statistically significant results point to agreement among the rankings of coefficients for the MACS components, and the effectiveness measures, thus adding validity to the convergent structural pattern.

\subsubsection{Possible industry effects}

One problem with generating gestalts is the potential for industry effects to limit the analysis, especially with the present sample (see Williams \& Seaman, 2001). To check for industry effects, we partition the total sample into a sector X median-split for the set of moderating variables as presented in Table 4 . The only discrepancy occurs in the service sector where the frequency for the high capacity subgroup is somewhat low, but the effect on the canonical analysis is immaterial. 
As a final check on the internal consistency of the canonical tests, we examine seven performance measures $\mathrm{X}$ sector regressions (21 in total), regressing each effectiveness measure against the set of changes in MACS components. Only four regressions are significant at $\mathrm{p}<0.10$ and they emerge under four different effectiveness measures (i.e. quality, goal attainment, reputation and morale). We conclude that no single performance measure is driving the canonical results. Also, out of 105 potentially significant coefficients for changes in MACS components only 6 emerge at $\mathrm{p}<0.10$ (three for planning, and one each for costing, directing and decision-making systems), with a split between positive and negative signs. Again we conclude that there are no abnormalities in the canonical generating process.

\subsection{Discussion}

This study provides evidence that a set of variables representing changes in MACS components is significantly associated with a multidimensional set of operational performance measures at the organizational level. This relation holds under conditions of high centralization (H2a), a high level of competition (H3a), and high and low levels of organizational capacity for learning $(\mathrm{H} 4 \mathrm{a}$ and $\mathrm{H} 4 \mathrm{~b})$. These results essentially confirm the importance of the moderator variables influencing changes in MACS components that Libby \& Waterhouse (1996) and Williams \& Seaman (2001) report.

The findings also support arguments in the literature claiming that a single aggregate measure of effectiveness, even at the operational level, does not adequately capture the interactive complexity of accounting control system components or their changes. In addition, different critical components of MACS change are associated with different critical performance outcomes under the various contingencies, illustrating the tradeoffs anticipated in the literature and the need to control for contingency effects (Merchant, 1995; Chow et al., 1999; Harrison \& McKinnon; 1999).

Most surprising, though, is finding not just important clusters of variables but convergent patterns with common variables. Within the structural gestalt for instance, top decision-makers tend to concentrate on changes in controlling systems that enhance quality and morale. Furthermore, they tend to link changes in planning systems specifically to adjustments in output quantities, but downplay this strategy to limit the negative effects on the former relationship. Within the environmental gestalt, top managers elect to emphasize changes in decision-making systems to foster efficiency when the intensity of competition is high. They correspondingly eschew changes in costing systems, where shifting costs to products or different work units limits efficiency gains. Many factors may be responsible for these findings but one plausible explanation is that they manifest cultural preferences for a particular control strategy.

For example, consider the linkage that emerges for high centralization. It accords with the powercompliance strategy connected to a high power distance cultural dimension that is characteristic of Singaporean society (Hofstede, 1980, 1991, 1994; Harrison, 1992, 1993; O'Connor, 1995). Harrison \& McKinnon (1999), relying on the work of Lincoln et al. (1981), correctly point out though that power distance is not a unitary concept. But along with Bond (1991) and Hofstede $(1980,1991)$, they underscore the highly authoritarian and distanced nature of relationships that characterize Chinese hierarchies. For all practical purposes, the family and business infrastructures are inseparable and the ultimate goal of survival of the family business in Chinese society is immutable.

The essence of this goal is manifest in guanxi relationships that span years of nurturing to secure customer satisfaction and supplier confidence through sustained output quality. Thus, the power of the family patriarch is evident not just in decision making, giving orders and personally supervising their execution (Bond, 1991, p. 79), but in ensuring that guanxi connections are properly serviced with quality output. Therefore, an emphasis on controlling systems changes that measure team-based performance, organizational performance, customer satisfaction and quality (see Appendix), and which minimize individualistic and interpersonal dimensions (e.g. participatory planning systems), is both consistent with Chinese power norms (Lachman et al., 1994) and supports the structural gestalt shown in Figure 1. 
Core cultural values may also explain the preferred linkage of low and high levels of learning capacity to quality versus morale, respectively, via changes in controlling systems. For example, besides the power distance norm, Hofstede (1990, p.140) singles out uncertainty avoidance as the other dominant dimension that affects our thinking of cultural values at the organization level. But recent literature argues that the norm value of Confucian Dynamism for eastern Chinese cultures is more relevant than the uncertainty avoidance dimension (Hofstede, 1994; Chow et al., 1999), and Hofstede (1994, p. 11) re-labels the latter as Long-term Orientation versus Short-term Orientation. The point is that output quality is a longer-term effectiveness measure, and emphasizing changes in controlling systems that try to secure the continuance of the family business is a logical, and responsible, decision by the patriarch. Assuming limited economic resources, the control system/quality connection would demand first priority and would probably manifest itself at a lower level of learning capacity (i.e., fewer number of existing MACSs) first rather than at a higher level, consistent with the structural gestalt shown in Figure 1.

An explanation for the connection leading from high capacity to morale in Figure 1 may also be anchored in a core cultural value, but one that deals with the maintenance of collectivistic values. This core value dimension in Chinese society focuses on the family and in-group members (Kagitcibasi \& Berry, 1989; Harrison \& McKinnon, 1999) in terms of their cooperative and mutual well being. Williams \& Seaman (2001) summarize literature that identifies Singapore as a high collectivistic society and Lachman et al. (1994, p. 48) submit that this core Chinese value emphasizes group goals and moralistic leadership. In fact, Campbell $(1977$, p. 37) views morale as a group phenomena of organizational effectiveness that encompasses feelings of belonging, commitment and goal communality. To the extent that the sub-components of controlling systems capture their intended information characteristics (see Appendix), then their linkage to morale appears very plausible.

Thus, a high level of learning capacity is compatible with a shift towards more emphasis on morale because the expanded number of MACSs increases the probability that the primary concerns of quality output and survival have been addressed. Furthermore, this hierarchical ordering of core values to effect the convergence of changes in controlling systems (i.e., structural processes) and quality and morale (i.e., performance outcomes) under conditions of scarce economic resources is precisely supported in the theoretical literature (Lachman et al, 1994, p. 47). The structural gestalt displayed in Figure 1 manifests this process.

Several explanations can be put forward for the presence of the environmental gestalt, including the wider integration objectives for the firm-wide accounting control system as well as bridging ties to the core cultural values. However, it is important to recall that intensity of competition pertains to external referents that can change rapidly, such as prices, or unexpectedly, such as new quality demands, the emergence of new competitors, or unforeseen events in the distribution chain. These changes require immediate attention, and most likely from the pinnacle of the hierarchical structure; otherwise profitability and possibly firm survival are compromised.

Therefore, one explanation for the environmental pattern may be that decision-making systems feature information which is reported more frequently and broadly, and utilizes more non-financial measures. These characteristics may assimilate more readily with controlling systems but less so with traditional planning systems (Kaplan \& Norton, 1996; Otley \& Pollanen, 2001), as Figure 1 indicates. Secondly, the literature is virtually unanimous in underscoring flexible decision making as the cornerstone of operational efficiency and, hence, this connection is tenable. Continuing, improved operational efficiency tends to enhance all operational effectiveness measures, which could therefore explain the non-appearance of large negative coefficients in Table 3 for the moderating effects of high competition. Thirdly, the convergence of high competition and changes in decision-making systems may simply represent the preferred alignment with the hierarchical authority structure overarching Singaporean family-owned businesses.

At a broader level, and moving away from the gestalts, finding a lack of association between low centralization (i.e., decentralization) and the canonical relationship sharpens Harrison \& McKinnon's (1999, p. 493) caveat that the cross-cultural research literature "assume(s) an excessive simplicity" about the power distance dimension. Not all businesses in Singapore, however, feature highly centralized structures. On the contrary, family-owned Chinese businesses are notorious for operating core and non-core business operations simultaneously, particularly where there are more offspring in large families who are highly educated, entrepreneurial and opportunistic. These 
operations are more web-like than hierarchical (Loh, 2000). The point is that they are created by the powerful family patriarch and are still driven by the same set of core cultural values (Gilley, 2000).

We conjecture that these decentralized operations ${ }^{6}$ require more of the standard coordinating mechanisms generally acknowledged in the management and control literature (Bruns \& Waterhouse, 1975; Daft, 1986) independent of any core cultural values. Therefore, increased cross-operational use, displacements, new introductions or modifications to all of the MACS components is possible, with none emerging dominant in relation to the set of performance measures. Also, other factors of a mimetic nature (DiMaggio \& Powell, 1983) may encourage experimentation with different MACS components but with no serious commitment to operational effectiveness. This latter possibility may also explain the lack of association between low competitive environments and the canonical relationship.

\subsection{Limitations and future research directions}

This exploratory study draws upon a multidimensional framework and analyses to present further evidence on the issue of MACSs change at the organization level in a specific national cultural setting. The findings essentially display a complex architecture surrounding the phenomenon of changes in MACSs for the sample of Chinese family-owned businesses. Surprisingly, the complexity is reduced by the convergence of common variables in the MACSs component change/performance outcome linkage for specific structural and environmental contingencies. Most importantly, though, the two gestalts that emerge in this process appear to be anchored in a national setting that is dominated by Hostede's $(1980,1991)$ cultural dimensions of high power distance, high collectivism, and a longterm Confucian Dynamism orientation.

Since the current work explicitly builds on the sample developed by Williams \& Seaman (2001), it inherits the limitations pertaining to the general problems of survey research, reliability of respondents in reporting on past events, and the suitability of the time-period involved that they note. Moreover, the choice of canonical correlation analysis may be questioned because it is only one of several multidimensional techniques that could be accessed to explore multidimensional patterns or representations of MACS components and performance outcomes. Even more questionable, unfortunately, is that it comes with inherent interpretation obstacles, even after the issue of the stability of weights is satisfied. Selecting only maximum canonical coefficients for parsimonious reasons to create gestalts in this study is thus open to criticism since this procedure limits a more detailed analysis.

A more contentious shortcoming to some, perhaps, is the non-measurement of core national cultural values and drawing inferences from the literature instead, which prevents cross-validation of results and potentially weakens corresponding explanations that are inductively based. Also, reliance only on a survey questionnaire for data collection, despite initial interviews at the distribution stage, aggravates this problem as well as restricting objective confirmation of the ingroup status of respondents.

All of these limitations restrict the generalizability of this study's findings, which suggests that one fruitful direction for future research is to replicate this study with better reliability conditions and a larger sample if possible. A second direction is to replicate this study in other Chinese settings such as Taiwan, Hong Kong, and even main land China. Although size is an insignificant variable in this study, extensions to larger government controlled businesses and publicly listed firms is worthy of exploration as well as incorporating administrative functions in addition to operational processes. These organizations may differ in important ways, not just from the impact of national culture but in the manner by which they constitute and change the entire accounting control system. In all cases, refined theory, method and measurement of variables, especially culture, in the linkage from core cultural values to contextual factors, and on to the coupling of multi-dimensional MACSs change components and operational performance outcomes is warranted and challenging. The contingency effects of technology are particularly worthy of study since past research shows that it operates at the interface of management control system characteristics and micro level behavior in Singapore ( Lau, Liang \& Eggleton, 1995; O’Conner, 1995). Not only is a different gestalt likely, but it may be driven by peripheral (Lachman et al., 1994) rather than core values and this needs to be addressed. 
In summary, this study provides new directions for designing future research work in three understudied areas: the lack of attention devoted to changes in accounting control systems at the organization level; the failure to consider Chinese culture in smaller, family-controlled operations; and, the shift in emphasis from the import-export orientation of contemporary cross-cultural research at the micro level to developing holistic strategies of MACSs change at the firm level. A hallmark of economic activity throughout most of Southeast Asia is the enormous contribution to the gross regional product by a plethora SMEs, and not just Chinese, comparable in size to those sampled in this study. Their strategies for managing change in MACSs are lent inertia by specific objectives, both culture-bound in ways that are not yet understood. Globalization is not forcing them to merge with multinationals but it is creating opportunities for experimenting with different types of business combinations and partnership arrangements. Knowledge of gestalts, such as those emerging in this study, could guide new developments in accounting control systems to the appropriate MACS sub-components and perhaps lead to longitudinal research that monitors their evolving nature.

\section{References}

1 Blau, P. M. (1970). A formal theory of differentiation in organizations. American Sociological Review, 35, 201-218.

2 Bond, M. H. (1991). Beyond the Chinese face: insights from psychology. Oxford: Oxford University Press.

3 Brownell, P. (1982). The role of accounting data in performance evaluation, budgetary participation and organizational effectiveness. Journal of Accounting Research, spring, 12-27.

4 Bruns, W. J. Jr \& Waterhouse, J. H. (1975). Budgetary control and organizational structure. Journal of Accounting Research, autumn, 177-203.

5 Cameron, K. S. \& Whetten, D. A. (1981). Perceptions of organization effectiveness across organizational life cycles. Administrative Science Quarterly, 26, 525-544.

6 Campbell, J. P. (1977). On the nature of organizational effectiveness. In P. S. Goodman \& J. M. Pennings, (Eds.), New perspectives on organizational effectiveness, (pp. 13-55), San Francisco: Jossey-Bass.

7 Chenhall, R. H. \& Brownell, P. (1986). The effect of participative budgeting on job satisfaction and performance: role ambiguity as an intervening variable. Working paper, (May), La Trobe University, Australia.

8 Child, J. (1973). Parkinson's progress: accounting for the number of specialists in organizations. Administrative Science Quarterly, 18, 328-348.

9 Child, J. (1977). Organizations. New York: Harper and Row.

10 Child, J. (1981). Culture, contingency and capitalism in the cross-national study of organizations. In Cummings, L. L. \& Staw, B. M. (Eds.), Research in organizational behavior, 3, (pp. 303-356). Greenwich, CT: JAI Press.

11 Chow, C. W., Shields, M. D. \& Chan, Y. K. (1991). The effects of management controls and national culture on manufacturing performance: an experimental investigation. Accounting, Organizations and Society, $16,209-226$.

12 Chow, C., Kato, Y. \& Shields, M. (1994). National culture and the preference for management controls: an exploratory study of the firm-labor market interface. Accounting, Organizations and Society, 19, 381-400.

13 Chow, C. W., Kato, Y. \& Merchant, K. A. (1996). The use of organizational controls and their effects on data manipulation and management myopia: a Japan vs U.S. comparison. Accounting, Organizations and Society, 21, 175-192.

14 Chow, C. W., Shields, M. D. \& Wu, A. (1999). The importance of national culture in the design of and preference for management controls for multi-national operations. Accounting, Organizations \& Society, 24, 441-461.

15 Cohn, W. M., \& Levinthal, D. (1990). Absorptive capacity: a new perspective on learning and innovation. Administrative Science Quarterly, 35, 128-152.

16 Cooley, W. W. \& Lohnes, P. R. (1980). Multivariate data analysis. New York: Wiley.

17 Cooper, W. K., Sinha, K. \& Sullivan, K. (1995). Accounting for complexity in costing high technology manufacturing. European Journal of Operational Research, 85, 316-326.

18 Daft, R. L. (1986). Organization theory and design. Saint Paul, MN: West.

19 Daft, R. L. (1992). Organization theory and design. $4^{\text {th }}$ edition. Saint Paul, MN: West. 
20 DiMaggio, P. J. \& Powell, W. W. (1983). The iron cage revisited: institutional isomorphism and collective rationality in organizational fields. American Sociological Review, 48, 147-160.

21 Duncan, R. B. (1972). Characteristics of organizational environments and perceived environmental uncertainty. Administrative Science Quarterly, 17, 313-327.

22 Fisher, J. (1995). Contingency-based research on management control systems: categorization by level of complexity. Journal of Accounting Literature, 33, 24-53.

23 Flamholtz, E., Das, T. \& Tsui, A. (1985). Toward an integrative framework of organizational control. Accounting, Organizations and Society, 10, 35-50.

24 Gordon, L. A. \& Narayanan, V. K. (1984). Management accounting systems, perceived environmental uncertainty and organizational structure: an empirical investigation. Accounting, Organizations and Society, 9, 33-47.

Govindarajan, V. (1984). Appropriateness of accounting data in performance evaluation: an empirical examination of environmental uncertainty as an intervening variable. Accounting, Organizations and Society, 9, 125-135.

Granlund, M. (1997). The challenge of management accounting change. Doctoral manuscript. Turku School of Economics and Business Administration.

27 Granlund, M. \& Lukka, K. (1998). It's a small world of management accounting practices. Journal of Management Accounting Research, 10, 153-179.

Gilley, B. (2000). Pulling away: the younger generation's new ways of doing things could determine the fate of Chinese family firms, which account for a majority of the shares quotes on regional markets. Far Eastern Economic Review, February 10, 42-46.

Hage, J. \& Aiken, M. (1967). Relationship of centralization to other structural properties. Administrative Science Quarterly, 12, 72-91.

30 Harrison, G. L. (1992). The cross-cultural generalizability of the relation between participation, budget emphasis and job related attitudes. Accounting, Organizations and Society, 17, 1-15.

31 Harrison, G. L. (1993). Reliance on accounting performance measures in superior evaluative style - the influence of national culture, Accounting, Organizations and Society, 18, 319-339.

32 Harrison, G. L. \& McKinnon, J. L. (1999). Cross-cultural research in management control systems design: a review of the current state. Accounting, Organizations and Society, 24, 483-506.

33 Hofstede, G. H. (1980). Culture's consequences: international differences in work-related values. Beverly Hills, CA: Sage.

34 Hofstede, G. H. (1982). Scoring guide for values survey model. Arnhem: IRIC.

Hofstede, G. H. (1991). Cultures and organizations: software of the mind. London: McGraw-Hill.

Hofstede, G. (1994). Management scientists are human. Management Science, 40, 4-13.

Hopwood, A. G. (1972). An empirical study of the role of accounting data in performance evaluation. Journal of Accounting Research, 10, 156-182.

38 Hopwood, A. G. (1978). Towards an organizational perspective for the study of accounting and information systems. Accounting, Organizations and Society, 3, 3-13. Science Quarterly, 15, 318-329.

41 Kagitcibasi, C. \& Berry, J. W. (1989). Cross-cultural psychology: current research and trends. Annual Review of Psychology, 40, 493-531.

42 Kaplan, R. S. \& Norton, D. P. (1996). The balanced scorecard: translating strategy into action. Boston, MA: Harvard Business School Press.

43 Kimberly, J. R., and Evanisko, M. J. (1981). Organizational innovation: the influence of individual, organizational and contextual factors on hospital adoption of technological and administrative innovation. Academy of Management Journal, 24, 688-713.

$44 \quad$ Khandwalla, P. (1972). The effect of different types of competition on the use of management controls. Journal of Accounting Research, 10, 275-285.

45 Khandwalla, P. N. (1977). The design of organizations. New York: Harcourt Brace Jovanivich.

46 Katz, B. M. \& McSweeney, M. (1980). A multivariate Kruskal-Wallis test with post hoc procedures. Multivariate Behavioral Research, (July), 281-297. 
47 Kerlinger, F. N. (1973). Foundations of behavioral research. New York: Holt, Rinehart \& Winston.

48 Lachman, R., Nedd, A. \& Hinnings, B. (1994). Analyzing cross-national management and organizations: a theoretical framework. Management Science, 40, 40-55.

49 Lau, C. M., Liang, C. L. \& Eggleton, I. R. C. (1995). The impact of reliance on accounting performance measures on job-related tension and managerial performance: additional evidence. Accounting, Organizations and Society, 20, 359-381.

50 Libby, T. \& Waterhouse, J. H. (1996). Predicting change in management accounting systems. Journal of Managerial Accounting Research, 8, 137-150.

51 Lincoln, J. \& Kalleberg, A. (1990). Culture, control, and commitment. Cambridge, UK: Cambridge University Press.

52 Lincoln, J. R., Hanada, M. \& Olsen, J. (1981). Cultural orientations and individual reactions to organizations: a study of employees in Japanese owned firms. Administrative Science Quarterly, 28, 93-115.

53 Loh, H. Y. (2000). One dynasty, two empires: stepping out from father's shadow, The Straits Times, August 17, p. 54, Singapore.

54 Macintosh, N. B. \& Williams, J. J. (1992). Managerial roles and budgeting behavior. Behavioral Research in Accounting, 4, 23-48.

55 Merchant, K. A. (1981). The design of the corporate budgeting system: influences on managerial behavior and performance. The Accounting Review, (56), 813-829.

56 Merchant, K. A. (1985). Organizational controls and discretionary program decision making: a field study. Accounting, Organizations and Society, 10, 67-85.

57 Merchant, K. A. (1989). Rewarding results: motivating profit center managers. Boston, MA: Harvard Business School Press.

58 Merchant, K. A., Chow, C. W. \& Wu, A. (1995). Measurement, evaluation and reward of profit center managers: a cross-cultural field study. Accounting, Organizations and Society, 20, 619-638.

Miles, R. E. \& Snow, C. C. (1978). Organizational strategy, structure and process. New York: McGrawHill.

$60 \mathrm{Ng}, \mathrm{C}$. K. (1992). The cultural horizon of south China's emigrants in the nineteenth century: change and persistence. In Y. M. Cheung (Ed.), Asian traditions and modernization: perspectives from Singapore, pp. 1-30, Singapore: Times Academic Press for Centre for Advanced Studies, National University of Singapore.

61 O'Connor, N. G. (1995). The influence of organizational culture on the usefulness of budget participation by Singaporean-Chinese managers. Accounting, Organizations and Society, 20, 383-403.

62 Otley, D. T. (1978). Budget use and managerial performance. Journal of Accounting Research, 16, 122149.

63 Otley, D.T. (1980). The contingency theory of management accounting: achievement and prognosis. Accounting, Organizations and Society, 5, 413-428.

Otley, D. T. \& Wilkinson, C. (1988). Organization behavior: strategy, structure, environment, and technology. In K. Ferris, (Ed.), Behavioral accounting research: a critical analysis (pp. 147-170). Columbus, $\mathrm{OH}$ : Century VII Publishing. Otley, D. \& Fakiolas, A. (2000). Reliance on accounting performance measures: dead end or new beginning? Accounting, Organizations and Society, 25, 497-510.

Otley, D. \& Pollanen, R. M. (2000). Budgetary criteria in performance evaluation: a critical appraisal using new evidence. Accounting, Organizations and Society, 25, 483-496.

67 Perrow, C. (1961). The analysis of goals in complex organizations. American Sociological Review, 26, 854-866.

68 Perrow, C. (1970). Organizational analysis: a sociological view. Belmont, CA: Wadsworth.

Parsons, T. (1964). Social structure and personality. New York: Free Press.

Porter, M. (1996). What is strategy? Harvard Business Review, 74, 61-78.

Pugh, D. S., Hickson, D. J., Hinings, C. R. \& Turner, C. (1968). Dimensions of organizational structure. Administrative Science Quarterly, 13, 65-105.

72 Pugh, D. S., Hickson, D. J., Hinings, C. R. \& Turner, C. (1969). The context of organization structures. Administrative Science Quarterly, 14, 91-114.

73 Quinn, R. E. \& Cameron, K. (1983). Organizational life cycles and shifting criteria of effectiveness: some 
preliminary evidence. Management Science, 29, 33-51.

74 Rokeach, M. (1969). Beliefs, attitudes and values. San Francisco: Jossey-Bass.

75

\section{Endnotes}

1. The importance of holding the research setting constant in replicating previous studies is crystallized by Otley \& Fakiolos (2000), Otley \& Pollanen (2000) and Vagneur \& Peiperl (2000) who attempt to disentangle the longstanding Hopwood (1972) and Otley (1978) debate. Holding national culture constant in this study, however, still leaves open the issue of differences in organizational culture, which we do not address.

2. Self-rating data is used for accessibility reasons and because more objective data is not publicly available. Also, in this cross-industry study, matching other types of data is extremely difficult. However, instead of the "halo" problem arising here, the issue is biased responses from the top echelon of the family business (Merchant, 1981; Brownell, 1982; Chenhall and Brownell, 1986). This concern is somewhat alleviated by the full range of responses on the performance measures reported in Table 1.

3. Zero-order correlation coefficients for the sets of changes in MACS components and effectiveness measures show no abnormalities. As expected, there is a high degree of correlation among the criterion set variables because the single conceptual construct of effectiveness is multidimensional (Perrow, 1970; Daft, 1986). The components of MACSs change are likewise positively correlated, but moderately so, as they too are sub-dimensions of a larger conceptual construct of the organization's managerial control system. Checks of the correlation coefficients for each contingency sub-sample are qualitatively the same and, in particular, there are no negative correlations.

4. Two statistical checks accompany each separate canonical analysis. First, there is always concern that ordinal data generated by Likert-type scales contravene the assumption of normality associated with parametric MANOVA statistical tests. Also, our sub-sample sizes border on the theoretically appropriate minimum. Accordingly, we use a multivariate Kruskal-Wallis non-parametric test (Katz \& McSweeney, 1980) to compare against each parametric test. There are no qualitative differences in any of the reported significance levels. Secondly, the canonical weights are subject to instability (Cooley \& Lohnes, 1971) and our sub-sample sizes do not permit a median-split for a cross-correlation check. Therefore, we examine the canonical structure loadings for each test and find no significant reversals of signs relative to the canonical 
weights.

5. As Williams et al. (1990) report, the theoretical range of the standardized canonical coefficients (i.e., weights) is not constrained to plus or minus one because the canonical coefficients are not correlation coefficients. The SPSS-x program we use is generous in its range of -99 to +99 . However, the common interpretation in the literature is that weights in the vicinity of plus or minus one are extremely important relative to those closer to zero.

6. Libby \& Waterhouse (1996, p. 139) report a mean value of 37.50 for the decentralization measure and also find no association between this measure and MACSs change. To check on the reliability of our low level of centralization subgroup, we reverse score responses on the concentration of authority scale and adjust the number of items downward from 23 to 15 to match their items. The recalculated mean for the low-level subgroup is 45.85 , or approximately one standard deviation above their mean score.

\begin{tabular}{|c|c|c|c|c|}
\hline \multicolumn{5}{|c|}{$\begin{array}{c}\text { Table } 1 \\
\end{array}$} \\
\hline \multicolumn{5}{|c|}{ Descriptive statistics for operational measures $(n=93)^{\mathrm{a}}$} \\
\hline & & & Actual & Theoretical \\
\hline Variable name & Mean & S.D. & range & Range \\
\hline Planning & 0.94 & 1.21 & $0-5$ & $0-5$ \\
\hline Controlling & 0.86 & 1.45 & $0-5$ & $0-5$ \\
\hline Costing & 0.37 & 0.96 & $0-5$ & $0-5$ \\
\hline Directing & 0.54 & 0.86 & $0-3$ & $0-3$ \\
\hline Decision making & 1.00 & 1.38 & $0-5$ & $0-5$ \\
\hline Centralization & 74.68 & 7.98 & $49-90$ & $23-115$ \\
\hline Size & 74.00 & 1536.30 & $100-8000$ & $>100$ \\
\hline Capacity & 12.10 & 5.09 & $1-23$ & $0-23$ \\
\hline Competition & 17.90 & 3.37 & $8-24$ & $5-25$ \\
\hline Quantity & 3.73 & 0.77 & $1-5$ & $1-5$ \\
\hline Quality & 3.60 & 0.79 & $1-5$ & $1-5$ \\
\hline Innovation & 2.96 & 0.87 & $1-5$ & $1-5$ \\
\hline Reputation & 3.40 & 0.78 & $1-5$ & $1-5$ \\
\hline Goal attainment & 3.44 & 0.78 & $1-5$ & $1-5$ \\
\hline Efficiency & 3.38 & 0.79 & $1-5$ & $1-5$ \\
\hline Morale & 3.37 & 0.85 & $1-5$ & $1-5$ \\
\hline
\end{tabular}

${ }^{\mathrm{a}}$ Variable definitions: Planning = number of changes in planning systems; controlling = number of changes in controlling systems; costing = number of changes in costing systems; directing = number of changes in directing systems; decision making = number of changes in decision-making systems; size = natural logarithm of the number of employees; capacity = organizational capacity for learning; competition = intensity of competition.

\begin{tabular}{|c|c|c|c|c|c|c|c|}
\hline \multicolumn{8}{|c|}{ Table 2} \\
\hline \multicolumn{8}{|c|}{ Correlation matrix for changes in MACS components and effectiveness $(n=93)^{a}$} \\
\hline & Quantity & Quality & Innovation & Reputation & $\begin{array}{l}\text { Goal } \\
\text { attainment }\end{array}$ & Efficiency & Morale \\
\hline Planning & 0.182 & 0.011 & 0.002 & -0.079 & 0.043 & -0.180 & -0.095 \\
\hline Controlling & -0.198 & 0.038 & -0.155 & 0.085 & -0.103 & -0.113 & -0.123 \\
\hline Costing & -0.191 & $-.0266^{*}$ & 0.004 & -0.199 & -0.145 & $-0.254 *$ & $-0.269^{*}$ \\
\hline Directing & $-0.241 *$ & -0.172 & 0.039 & -0.155 & -0.134 & 0.198 & -0.116 \\
\hline $\begin{array}{l}\text { Decision } \\
\text { making }\end{array}$ & 0.044 & 0.049 & 0.015 & 0.029 & 0.066 & 0.031 & 0.020 \\
\hline
\end{tabular}

${ }^{a}$ Variable definitions: Planning = number of changes in planning systems; controlling = number of changes in controlling systems; costing = number of changes in costing systems; directing = number of changes in directing systems; decision making = number of changes in decision-making systems.

$*=$ significant at the $5 \%$ level, two-tailed test. 


\begin{tabular}{|c|c|c|c|c|c|}
\hline \multicolumn{6}{|c|}{ Table 3} \\
\hline \multicolumn{6}{|c|}{ Results of canonical correlation analyses $^{\mathrm{a}}$} \\
\hline & \multicolumn{5}{|c|}{ Standardized canonical coefficients } \\
\hline & Total & Centralization & Competition & Capacity & Capacity \\
\hline Variable & Sample & (high) & (high) & (low) & (high) \\
\hline \multicolumn{6}{|l|}{ Predictor set } \\
\hline Planning & -1.063 & -1.158 & -0.492 & 0.199 & -0.825 \\
\hline Controlling & 0.745 & 0.659 & -0.220 & 0.806 & 0.718 \\
\hline Costing & 0.145 & 0.187 & -0.791 & -0.509 & 0.373 \\
\hline Directing & 0.112 & -0.009 & -0.368 & -0.918 & 0.025 \\
\hline Decision making & 0.150 & 0.369 & 0.715 & -0.339 & 0.070 \\
\hline \multicolumn{6}{|l|}{ Criterion set } \\
\hline Quantity & -1.168 & -0.918 & -0.066 & 0.331 & -0.914 \\
\hline Quality & 0.467 & 0.768 & 0.065 & 0.599 & -0.039 \\
\hline Innovation & -0.093 & 0.006 & -0.197 & -0.080 & -0.432 \\
\hline Reputation & 0.081 & -0.372 & 0.389 & -0.348 & 0.487 \\
\hline Goal attainment & -0.140 & 0.369 & 0.064 & 0.430 & -0.470 \\
\hline Efficiency & 0.494 & 0.713 & 0.689 & 0.227 & 0.255 \\
\hline Morale & -0.132 & -0.389 & -0.001 & -0.172 & 0.730 \\
\hline Sample size & 93 & 49 & 46 & 49 & 44 \\
\hline Canonical $\mathrm{r}$ & 0.512 & 0.705 & 0.713 & 0.688 & 0.690 \\
\hline Wilks lamda & 0.518 & 0.295 & 0.211 & 0.268 & 0.222 \\
\hline Probability & 0.013 & 0.044 & 0.006 & 0.019 & 0.018 \\
\hline Eigenvalue & 0.356 & 0.989 & 1.032 & 0.897 & 0.907 \\
\hline$\%$ variance explained & 48.1 & 62.4 & 50.4 & 53.9 & 47.1 \\
\hline
\end{tabular}

${ }^{\mathrm{a}}$ Variable definitions: Planning = number of changes in planning systems; controlling = number of changes in controlling systems ; costing $=$ number of changes in costing systems; directing $=$ number of changes in directing systems; decision making $=$ number of changes in decision-making systems; size = natural logarithm of the number of employees; capacity = organizational capacity for learning; competition = intensity of competition.

\begin{tabular}{|c|c|c|c|}
\hline \multicolumn{4}{|c|}{ Table 4} \\
\hline \multicolumn{4}{|c|}{ Frequency by sector within low/high contingency variables a } \\
\hline & Manufacturing $(\mathrm{n}=25)$ & Industrial $(n=42)$ & Service $(n=26)$ \\
\hline $\begin{array}{l}\text { Centralization: } \\
\text { Low } \\
\text { High }\end{array}$ & $\begin{array}{l}11 \\
14\end{array}$ & $\begin{array}{l}21 \\
21\end{array}$ & $\begin{array}{l}12 \\
14\end{array}$ \\
\hline $\begin{array}{l}\text { Competition: } \\
\text { Low } \\
\text { High } \\
\end{array}$ & $\begin{array}{l}10 \\
15\end{array}$ & $\begin{array}{l}24 \\
18 \\
\end{array}$ & $\begin{array}{l}13 \\
13\end{array}$ \\
\hline $\begin{array}{l}\text { Capacity: } \\
\text { Low } \\
\text { High }\end{array}$ & $\begin{array}{l}12 \\
13\end{array}$ & $\begin{array}{l}19 \\
23\end{array}$ & $\begin{array}{r}18 \\
8\end{array}$ \\
\hline
\end{tabular}

${ }^{a}$ Variable definitions: capacity = organizational capacity for learning; competition = intensity of competition. 


\begin{tabular}{|c|c|c|c|c|c|c|c|}
\hline \multicolumn{8}{|c|}{ Figure 1} \\
\hline \multicolumn{8}{|c|}{ Convergent patterns $^{\mathbf{a}}$} \\
\hline & & & MACS component & & & Effectiveness & \\
\hline \multirow[t]{3}{*}{ Construct } & Contingency & & Emphasis & De-emphasis & & Emphasis & De-emphasis \\
\hline & Centralization $(\mathrm{H})$ & & Controlling & Planning & & Efficiency & Quantity \\
\hline & & & & & & Quality & \\
\hline \multirow[t]{2}{*}{ Structure } & Capacity (L) & $\longrightarrow$ & Controlling & Directing & $\longrightarrow$ & Quality & - \\
\hline & Capacity $(\mathrm{H})$ & & Controlling & Planning & & Morale & Quantity \\
\hline & & & & & & & \\
\hline & & & & & & & \\
\hline Environment & Competition $(\mathrm{H})$ & $\longrightarrow$ & DM & Costing & $\longrightarrow$ & Efficiency & - \\
\hline & & & & & & & \\
\hline
\end{tabular}

${ }^{\mathrm{a}}$ Variable definitions: Planning = number of changes in planning systems; controlling = number of changes in controlling systems; costing = number of changes in costing systems; directing = number of changes in directing systems; $\mathrm{DM}=$ number of changes in decision-making systems; capacity $=$ organizational capacity for learning; competition = intensity of competition. Notation: $(\mathrm{L})=$ low level; $(\mathrm{H})=$ high level. 


\section{Notes}

